University of Texas Rio Grande Valley

ScholarWorks @ UTRGV

\title{
How Much Does Physical Attractiveness Matter for Blacks? Linking Skin Color, Physical Attractiveness, and Black Status Attainment
}

Igor Ryabov

The University of Texas Rio Grande Valley, igor.ryabov@utrgv.edu

Follow this and additional works at: https://scholarworks.utrgv.edu/soc_fac

Part of the Gender and Sexuality Commons

\section{Recommended Citation}

Ryabov, I. How Much Does Physical Attractiveness Matter for Blacks? Linking Skin Color, Physical Attractiveness, and Black Status Attainment. Race Soc Probl 11, 68-79 (2019). https://doi.org/10.1007/ s12552-018-9245-1

This Article is brought to you for free and open access by the College of Liberal Arts at ScholarWorks @ UTRGV. It has been accepted for inclusion in Sociology Faculty Publications and Presentations by an authorized administrator of ScholarWorks @ UTRGV. For more information, please contact justin.white@utrgv.edu, william.flores01@utrgv.edu. 


\title{
How Much Does Physical Attractiveness Matter for Blacks? Linking Skin Color, Physical Attractiveness and Black Status Attainment
}

\begin{abstract}
The accumulated evidence suggests that lighter-complected blacks are more successful in our society that their darker-complected counterparts. Prior research also documents a correlation between physical attractiveness and socio-economic status attainment. The current study bridges the literatures on colorism and physical attraction and examines the complex relationship between skin color, physical attractiveness, gender, on the one hand, and three indicators of status attainment (educational attainment, hourly wage and job quality), on the other, for black young adults. Controls include family SES, family structure, parent-child relationships and other covariates. Analysis was conducted in STATA and via structural equation modeling using MPlus software. The analysis shows that lighter skinned young blacks attain a higher educational level, receive higher wages and enjoy better quality jobs than their darker skinned co-ethnics. Moreover, the results show that more physically attractive young blacks, especially women, are advantaged in terms of educational attainment, wages and job quality than their less physically attractive counterparts. These findings suggest that, among blacks, the skin color stratification coincides with that based on physical attractiveness to a large degree, with the implication being that the skin tone is a predictor of both physical attractiveness and social status for black men and women.
\end{abstract}




\section{Introduction}

Contemporary American society places extraordinary emphasis on physical attractiveness, culturally determined standards of male and female beauty (Hosoda et al. 2003; Jæger 2011; Langlois et al. 2002; Robins et al. 2011). People who are perceived as physically attractive enjoy many advantages, while unattractive individuals are disadvantaged both socially and economically (French et al. 2009; Hosoda et al. 2003; Marlowe et al. 1996). Abundant empirical research has shown that physical attractiveness is positively correlated with educational achievement (French et al. 2009; Zebrowitz et al. 2002), higher wages, salaries and other labor market outcomes (Baert and Decuypere 2014; Fletcher 2002; Hosoda et al. 2003; Ruffle and Shtudiner 2014). It has also been observed that colorism, a system of racial stratification and social privilege that favors light complexion over dark complexion, plays a central role in defining standards of beauty for African Americans (hereafter blacks) (Harvey et al. 2005; Maddox and Gray 2002; Thompson and Keith 2001). Numerous studies have shown the many ways in which colorism affects the African American community (Hannon et al. 2013; Hochschild and Weaver 2007; Saperstein and Gullickson 2013; Ryabov 2013).

Although a relationship between perceptions of attractiveness and racialized standards of beauty has been established by prior research, no studies have so far explored the complex relationship between skin tone, physical attractiveness and professional career success for blacks. The current study is intended to address this shortcoming of the past research by examining the mediating role of physical attractiveness on the relationship between skin color and three indicators of attained status - educational attainment, hourly 
wage, and job quality - among black young adults. The present article contributes to the research literature in various ways. First, we develop predictive models of status attainment for black young adults using a large longitudinal dataset-the National Longitudinal Study of Adolescent Health (the Add Health) — in attempt to disentangle the effects of physical attractiveness and skin color. Second, we approach social status attainment as three related, but different outcomes_educational attainment, wage and job quality. Finally, this work integrates two strands of literature: one on social stratification and the other one on colorism to explore the complex, interwoven relationships between skin tone, physical attractiveness and attained social status.

\section{Historical Roots of Colorism}

While the weight of scholarly evidence suggests that colorism as a global phenomenon is the product of European colonialism, the origin of colorism in America harkens back to slavery (Hunter 2007; Saperstein and Gullickson 2013). A number of writings on the comparative history of slavery attest to the fact that, although slavery is not uniquely American experience, slavery in the U.S. was harsher on blacks than it was in other former European colonies in the Western Hemisphere (Bergad 2007; Dodoo 1997; Model 2008; Sowell 1978). For example, before the closing of the Trans-Atlantic slave trade, slaveowners in the U.S. preferred to import rather than to rear slaves, while their counterparts in the British West Indies and Latin America normally opted for the former (Bergad 2007; Kolchin 2003). Before and shortly after the independence of the U.S. from the Great Britain, slave mortality was extremely high, while fertility was so low that most 
planters in the U.S. depended heavily on a constant inflow of slaves from Africa (Kolchin 2003; Cole 2005). In order to support the cruel exploitation of slave labor, the privileged white class enforced a rigid color code as a tool of ideological domination. As a reflection of this, the United States inherited from the slavery period, arguably, the toughest antimiscegenation laws in the world (Bratter and O'Connell 2017). Although these laws are no longer on the books thanks to the Civil Rights movement, they had a profound effect on the way blackness is defined in the U.S. Therefore, premium placed on the lightness of skin has always been higher for African Americans than for other people of African descent in the Americas (Dixon and Telles 2017; Hall 2003).

Historical accounts suggest that phenotypic hierarchy appeared early in the slavery period with the emergence of light-complected slaves of mixed ancestry who as the result of the systematic sexual violence of white slaveowners against blacks (Edwards 1959; Frazier 1957; Myrdal 1944). These slaves were more likely to be granted domestic positions, better food and clothing, and manumission and educational opportunities (Bodenhorn 2002; Hunter 2007; Keith and Herring 1991; Saperstein and Gullickson 2013). According to Myrdal (1944), slaves of mixed African and European descent were higher valued in the slave market and were preferred as personal servants because they were considered to be aesthetically and intellectually superior to slaves of pure African descent. A fair complexion significantly improved slaves' chances of survival by reducing their toil and by improving their access to food and shelter. Thus, slaves who were more European in appearance often became house slaves, while those with pure African ancestry were relegated to toil as field slaves (Cole 2005; Bodenhorn and Ruebeck 2007; Keith and 
Herring 1991). Moreover, the superiority of light-complected over dark-complected blacks was widely accepted in the free black population as a whole (Edwards 1959; Hall 2003).

Status distinction by skin tone lingered long after slavery. In the South, lightcomplected blacks became the social and economic elite of black communities. Although their jobs as small entrepreneurs and public servants were not prestigious in the modern sense, these were privileged positions compared with the opportunities available to other blacks. While some studies assert that colorism has diminished in the aftermath of the civil rights movement (Goering 1972; Gullickson 2005; Udry et al. 1971), there is a strong evidence that phenotype still determines a black person's educational and professional career to a large extent (Goldsmith et al. 2007; Hochschild and Weaver 2007). Recent studies show that, compared to their lighter-complected counterparts, darker-complected blacks are still penalized in the labor market, in terms of wages and the positions they occupy (Allen et al. 2000; Hill 2000; Monk 2015).

\section{Colorism and Beauty Standards}

It has been observed that physical attractiveness as a criterion of social stratification overlaps with phenotype (Awad et al. 2015; Hill 2002; Hunter 2002; Keith et al. 2017; Mbure and Aubrey 2017). This is because colorism is intrinsically linked to beauty standards through the shared focus on skin color, and other phenotypically important features such as hair texture, nose and lip shape (Hall 2005; Hunter 2002; Weitz 2001). For racial minorities like blacks, adherence to a perceived standard of beauty may be even more crucial than for whites because attractiveness may compensate for minority status 
(Awad et al. 2015; Solorzano et al. 2000). Unfortunately for blacks, the mainstream standards of beauty in the American society are racialized: they are based on models of the majority group, non-Hispanic whites, who differ from blacks both genetically and phenotypically. Following these standards of beauty for blacks is not only expensive but also can have numerous detrimental psychological and health repercussions (Parmer et al. 2004; Mbure and Aubrey 2017; Thompson and Keith 2001; Wade and Bielitz 2005). However, this distress is alleviated for lighter-skinned blacks who possess phenotypes similar to non-Hispanic whites (Borrell et al. 2006; Wade and Bielitz 2005; Weitz 2001). Consequently, these light-complected blacks easily reap the benefits associated with perceived attractiveness (Borrell et al. 2006; Hall 1995; Monk 2015; Trekels et al. 2018).

A few studies have examined the link between colorism and attractiveness among African Americans. Using data from the 1979-80 the National Survey of Black Americans (NSBA), Hill (2002) found that lighter skin tone was associated to higher ratings of physical attractiveness for black adults and this association was stronger for women than for men. More recently, Sims (2012) and Reece (2016), both using the Add Health data, have demonstrated that the relationship between phenotype and beauty standards holds true for blacks, yet is more complex than has traditionally been thought. Using the concept of "biracial beauty stereotype," that is a belief that biracial people are more attractive than monoracial people, Sims (2012) argued that physical attractiveness, either self-perceived or externally rated, has an effect on one's racial identify. Although her results were mixed, they held true for people of African descent. Reece (2016) reversed the causal direction that the Sims' (2012) analysis followed, while showing that multiracial self-identification influences physical attractiveness among people of African ancestry. The findings of 
Reece's (2016) study demonstrated that black individuals of mixed ancestry are externally perceived as more attractive than black individuals of pure African ancestry. Overall, the above studies strongly suggest that proximity to the white phenotype among blacks is positively related to the perception of physical attractiveness.

\section{Colorism and Gender}

One of the most consistent observations derived from an extensive literature on physical attractiveness is that men and women differ in the importance of the effect of attractiveness (Greitemeyer 2010; Meltzer et al. 2014; Grabe and Hyde 2006). Around the world and throughout history, men more than women preferred a physically attractive marriage partner (Eastwick et al. 2014; Schwarz and Hassebrauck 2012). Moreover, women are subject to a lot of pressure from a larger society to conform to the ideal of feminine beauty (Hill 2002; Parmer et al. 2004). In a society that emphasizes a cultural ideal of female beauty, men and women are subject to different normative expectations for behavior. Though this is not a focal point of the present article, there is strong evidence that disturbances in body image are more common among women than among men (Furnham et al. 2002; Grabe, and Hyde 2006; Grabe et al. 2008; Gray and Boothroyd 2012; Parmer et al. 2004). Thus, there is a reason to believe that, regardless of race/ethnicity, physical attractiveness is a more important factor for women than for men.

Prior research unequivocally indicates that adherence to beauty standards, one way in which people comply or conform to culturally dominant norms, disproportionately affects black women rather than black men (Grabe and Hyde 2006; Thompson and Keith 
2001). Colorism is gendered because of the close link between racialized beauty standards and perceptions of physical attractiveness, and because of a double standard that applies beauty standards more rigidly to women. In a society where proximity to white phenotype and, especially, lightness of skin is a highly valuable component of female beauty, women with darker skin and Afrocentric features are at a disadvantage. Therefore, it is possible that colorism has a differential effect on socio-economic outcomes of black males and females.

\section{Present Study}

Social stratification research clearly documents that socio-economic success depends on physical attractiveness (French 2002; Hosoda et al. 2003; Ruffle and Shtudiner 2014). Following the pioneering studies of Gowin (1915), Perrin (1921) and Waller (1934), empirical research has demonstrated that physical attractiveness is linked to a multitude of positive personality characteristics. For example, people who are physically attractive tend to be more self-confident, healthier and happier than less attractive individuals (e.g., Judge et al. 2009; Mobius and Rosenblat 2006; Nedelec and Beaver 2014; Reither et al. 2009). Even more importantly, physical attractiveness is positively associated with a number of socio-economic outcomes (e.g., Fletcher 2009; Hosoda et al. 2003; Mobius and Rosenblat 2006; Pfeifer 2012). For example, Hamermesh (2011) estimated the size of the "beauty premium," a bias specific to appearance, to be equivalent to the race and gender gaps in wages. However, much remain unknown about the relationship between attractiveness and social status across race/ethnic groups, including 
U.S. blacks. Furthermore, the question of whether this relationship holds empirically when the effect of colorism is taken into consideration has not been addressed.

\section{Hypotheses}

In line with the persistent stratification by color among blacks evident in the wealth of literature, we offer the following hypotheses that capture how colorism, physical attractiveness and gender related to three measures of attained status for black young adults:

Hypothesis 1: Given that beauty is a positive status characteristic and physically attractive individuals benefit economically from their status (French et al. 2009; Hosoda et al. 2003; Langlois et al. 2000), we believe that physical attractiveness among blacks will be positively associated with status attainment in young adulthood. In other words, more physically attractive individuals will be likely to capitalize on their attractiveness.

Hypothesis 2: We expect to find an indirect effect of phenotype on status attainment through attractiveness, net of socio-economic background and other controls. Thus, we consider physical attractiveness as a potential mediator and estimate the indirect effect of skin color on status attainment measures (educational attainment, hourly wage and job quality) via physical attractiveness. This effect is hypothesized because the

prevalence of white beauty standards in the U.S. puts lighter-complected blacks in advantage over their darker-lighter complected counterparts (Hall 2005; Hill 2002; Sims 2012; Wade and Bielitz 2005). 
Hypothesis 3. We consider gender as a moderator and examine the extent to which the relationships between skin tone and attractiveness and between attractiveness and status attainment differ as a function of gender. Moreover, we believe that the aforementioned relationships will be stronger for females, based on the assumption of greater importance of attractiveness for females in our culture (Hill 2002; Parmer et al. 2004). Hence, the strength of the relationships between skin tone and status attainment and between physical attractiveness and status attainment is likely to vary as a function of skin tone.

\section{Methods}

\section{Data and Sample}

For this study we use data from Waves 1, 3 and 4 of the National Longitudinal Study of Adolescent Health (The Add Health). The Add Health is a multiple-wave, nationally representative sample of adolescent students. The Add Health's methodology have been described in detail elsewhere (Harris et al. 2009). Four waves of data were collected in 1994-95, 1996, 2001-2002, and 2008-2009, respectively. In Wave I of the Add Health, researchers sampled 20,745 students who were in grades 7-12 at 142 schools across the country. Our final sample includes only African-American respondents $(\mathrm{N}=$ $2,456)$ only with valid weights and no missing values on the key variables in Waves 1,3 and 4 . Thus, the analytical sample included only data with non-missing values. Missing data analysis showed that showed that $89 \%$ respondents had no missing values for the 
entire set of study variables. We compared respondents with and without missing values on all variables (skin tone, attractiveness, gender, educational attainment, hourly wage, job quality and the controls). This auxiliary analysis confirmed that there was no statistically significant difference between respondents without missing data in our study sample and those with incomplete data. It is also important to mention that our analysis is based on weighted data to account for unequal probability of selection and survey non-response.

\section{Dependent Variables}

Three measures of social status are examined in this study: (1) educational attainment; (2) hourly wages; and (3) job quality. All three outcomes were measured at Wave 4. Educational attainment ranges from $1=$ 'less than high school' to $5=$ 'more than a 4-year degree'. More than $96 \%$ of the black participants in our sample report an hourly wage. For the rest, we construct an hourly wage by dividing annual personal income by the hours worked per week multiplied by 50 . To deal with skewness, hourly wage was transformed using the Box-Cox family of log-linear transformations (Osborne 2010). This procedure determines the best transformation to normality by maximum likelihood.

While the first two outcomes are standard indicators of SES, job quality, a composite variable, refers to intrinsic rewards that the respondents obtain through their current or most recent jobs. Following Wickrama et al. (2012), the measure of job quality was constructed by averaging responses to three items: decision-making autonomy, repetitiveness of tasks and supervisory responsibilities. These items corresponded to the following questions from the Add Health survey. Decision-making autonomy: "How often 
do you have the freedom to make important decisions about what you do at work and how you do it?' Responses ranged from $0=$ 'none' to $3=$ 'all the time'. Repetitiveness of tasks: "How much of the time do you do the same things repeatedly?" Responses ranged from 0 $=$ 'none' to $3=$ 'all the time'. This item was reverse coded so that a higher score corresponded to a lower level of repetitiveness. Supervisory responsibilities: "Thinking about your official job duties, which of the following statements best describes your supervisory responsibilities at your job?" Responses ranged from $1=$ 'supervise other employees' to $3=$ 'do not supervise other employees'. This item was reverse coded so that a higher score indicated a higher level of supervisory responsibilities. By averaging the above items, we created a scale with higher values indicating a higher job quality. Cronbach's alpha for this scale was 0.71 .

\section{Key Independent Variables}

At the conclusion of each wave of data collection (Waves 1, 2, 3 and 4), the Add Health interviewers completed a number of questions about the respondent characteristics. Included within these items was the question of how physically attractive the respondent was. A 5-point scale was used to create the attractiveness measure, with responses ranging from." Thus, possible scores ranged from $1=$ 'very unattractive' to $5=$ 'very attractive'. Although attractiveness records were very close across all four waves (Cronbach's alpha across four waves of data collection was 0.87 ), in our analysis the scores were averaged across Waves 1-4 to minimize the influence of interviewer bias. It has also been noticed that the interviewers tended to be generous in their assessment, thus assigning above 
average attractiveness to more than $65 \%$ of the respondents (Robins et al. 2011). Therefore, to reduce skewness in the data, we transformed attractiveness scores using the Box-Cox algorithm (see above).

Skin tone was measured at Wave 3 of the Add Health. The categories of the variable 'skin tone', as it was constructed by the Add Health, allowed distinguishing adolescents with black, dark brown, medium brown and light brown skin tones. Although we realize that retaining the original coding maximizes our ability to detect nuanced differences in the skin tone effect, we decided to analyze skin tone as an interval-level variable, and not as a categorical variable (ranging from $1=$ 'black' to 4 = 'light brown'). This is done in order to avoid partitioning error variance of skin tone variable while estimating the interaction terms of gender and skin tone and of gender and attractiveness. Our auxiliary statistical tests (not shown for parsimony) have shown that the interaction terms of attractiveness and each of the four categories of skin tone are redundant variables deflating the model fit values.

\section{Control Variables}

In addition to our primary explanatory variables, attractiveness and phenotype, we control for a variety of other characteristics that may affect social status attainment, including family effects (SES, family structure and quality of parent-child relationship), gender, age, marital status and neighborhood disadvantage. All, except age and marital status, were measured at Wave 1. Three measures - income, educational attainment and occupational prestige of the respondent's parents - were used to control for SES of family 
of origin, an important determinant of own SES. Parental education was recoded to reflect the highest level of attainment of either parent. Because all three SES measures were strongly intercorrelated (Cronbach's alpha $=0.76$ ), we created the aggregate family SES score as the average of the standardized scores of parental income, educational attainment and occupational prestige. Internal consistency of family SES score has been described in detail elsewhere (e.g., Bearman et al. 2004).

Following Coleman (1988), we control for structural (e.g., family structure) and qualitative (e.g., the quality of parent-child relationship) family effects. Specifically, we compare respondents who were raised in two-parent families (reference) to those who resided in either a single-parent or non-parent household (i.e., with a guardian, usually a relative) when Wave 1 data were collected. Three different scales, all of which were measured at wave 1 of the Add Health data, were included to control for parent-child relationships. All these scales have been used by previous researchers (Haynie 2001; Schreck et al. 2004).

The first scale, parental involvement, gauges the extent to which the respondent's parents were involved in their lives in childhood. The scale was constructed from ten items that inquired into the activities that the respondent participated in with their parent or guardian in the past month. The items included: gone shopping; played a sport; talked about life; talked about a date or party attended; attended a religious service or related event; attended a movie, sports event, concert, play, or museum; talked about a personal problem; discussed grades or school work; worked on a school project; talked about other school activities. The items were averaged, where higher scores indicate higher parental involvement (Cronbach's alpha $=0.72)$. 
The second scale, parental attachment, is a four-item index that captures how strongly bonded the subjects were with their parents. The Add Health respondents were asked how close they felt with their father and mother and how much they thought that their father and mother cared about them. These four items were then averaged to create an index $($ Cronbach's alpha $=0.78)$. Parental attachment scores range from 1 to 5 , with a higher score signifying greater attachment.

Parental engagement, the third parent-child relationship scale, contains five items. At wave 1, respondents were asked to indicate their level of agreement with five statements related to their relationships with their parents. These statements included items regarding whether their mother was encouraging of independence, whether the mother talks to them about why particular behaviors are wrong, if the mother or father were warm and loving, if the youth was satisfied with the ways he or she communicates with his or her mother or father, and if the youth was satisfied with his or her relationships with the mother and father overall. Each item was measured on a 5-points scale. These five items were averaged to produce an index (Cronbach's alpha $=0.76)$.

\section{Analytic Strategy}

Structural Equation Modeling (SEM) was used in this paper to test the hypothesized relationship between skin tone, physical attractiveness, gender, and status attainment, while controlling for a range of individual socio-economic and family effects. Unlike regression analysis, SEM permits simultaneous testing of models with multiple dependent variables and modeling of mediating and moderating variables. Moreover, 
whereas regression is highly prone to errors of misspecification, the SEM offers a more robust strategy by comparing alternative models using a battery of fit statistics. As shown by the hypotheses, this article offers a theoretical model that joints multiple dependent variables, and a moderating variable, gender. Given these characteristics, the author judges that SEM is an appropriate analytical tool.

The descriptive statistics were obtained using STATA, while MPlus was utilized for SEM. Models with robust standard errors were used to account for clustering of participants within schools. The final model is compared to plausible alternative models where all the hypothesized effects are set to zero. The alternative models provide a baseline against which to compare the final model. To determine the fit of the final model we report three goodness-of-fit indices: the chi-square $\chi^{2}$ (large significant values indicate a poor fit, whereas small insignificant values indicate that the model fits the data well); the Comparative Fit Index (CFI; with values exceeding .90 indicating a good fit); and the Root Mean Squared Error of Approximation (RMSEA, where values above .05 indicate good fit) (for more detail see Schermelleh-Engel et al. 2003). Visualization of structural equation models is achieved with path diagrams. Below we present the path diagrams per each outcome.

\section{Results}

Descriptive statistics and correlations 
Table 1 contains a summary of the study variables separately for black males and females. Except for those indicators that were transformed using the Box-Cox family of log-linear transformations (see above), the skewness and kurtosis values for the rest of the study variables met the criteria for normality. We present the study variables separately by gender. This was done because there are quite a few gender-related differences in the levels of skin tone, physical attractiveness and a few other variables. Examination of skin tone also reveals that, on average, black females are lighter completed than males. The average skin tone value for females is 2.0 , as compared to 1.8 for males (see Table 1 ). As our additional analyses show (t-tests are not shown for parsimony), this difference is significant at $\mathrm{p}<.05$. Likewise, a statistically significant difference was found between black males and females in physical attractiveness (2.31 for males versus 2.78 for females). Although we found no significance difference in the means for educational attainment (2.26 for males and 2.28 for females), compared to black females, black males seem to enjoy better wages and job quality (t-tests are not shown).

[Table 1 is about here]

Next, drawing on Table 2, we discuss significant bivariate correlations between the study variables. We find that all outcome variables are moderately correlated, which is not surprising given that they tap into the same concept - status attainment. The strongest correlation is between educational attainment and wage (Pearson's $\mathrm{r}=.63$ ). The correlation between key independents variables, skin tone and physical attractiveness, is also significant and positive (Pearson's $\mathrm{r}=.44 ; \mathrm{p}<.01$ ). Furthermore, both skin tone and physical attractiveness appear to have been correlated to all three outcome measures, with the strength of the relationships varying from $\mathrm{r}=.24$ (between physical attractiveness and 
educational attainment) to $\mathrm{r}=.39$ (between skin tone and job quality). That is, skin tone and physical attractiveness are likely to predict educational attainment, hourly wage and job quality. The correlation analysis also corroborates the descriptive findings on gender differences in skin tone and attractiveness. There are negative correlations between being male and skin tone (Pearson's $\mathrm{r}=-.22 ; \mathrm{p}<.05$ ) and between being male and physical attractiveness (Pearson's $\mathrm{r}=-.36 ; \mathrm{p}<.01$ ). Moreover, male gender is positively correlated to wage and job quality, but not to educational attainment. Before proceeding to the multivariate analysis, it is worthwhile to check for multicollinearity. We ran a series of regressions in which each predictor was regressed on all other predictors and examined the variance inflation factor (VIF) for each of the explanatory variables. The highest value of VIFs that we reached was 3.4, indicating that multicollinearity was not an issue (Hair et al. 2010).

[Table 2 is about here]

\section{Path Analysis}

Figure 1 displays the results of the path analysis predicting educational attainment as a path diagram. Controlling for other variables, the path coefficient (a.k.a. standardized regression coefficient) from skin tone to educational attainment $(\beta=.26 ; p<.01)$ indicates that blacks with lighter skin tone attain a higher educational level than blacks with darker skin tone. The relationship between skin tone and educational attainment is mediated by physical attractiveness. As Figure 1 illustrates, the path coefficient between skin tone and physical attractiveness is positive and statistically significant $(\mathrm{p}<.01)$, as is the standardized 
regression coefficient between physical attractiveness and educational attainment. The standardized indirect effect is $(.53)(.42)=.22$. Compared to the truncated model in which the effect of physical attractiveness is set to zero, the final model presents a better fit. Although in both models the data provide good fit $\left(\chi^{2}\right.$ is nonsignificant; CFI well exceed the value of .95 and RMSEA is below 0.05$)$, the difference in $\chi^{2} / \mathrm{df}$ between the full and truncated models is significant, thus implying that the full model explains the data better. Although the interaction effect of skin tone and gender on educational attainment was nonsignificant, this path was retained as part of the final model. However, gender is found to moderate the impact of attractiveness on educational attainment $(\mathrm{p}<.05)$. The negative path coefficient $(\beta=-.23 ; \mathrm{p}<.05)$ indicates that the relationship between attractiveness and educational attainment is weaker for males.

[Figure 1 is about here]

Path analysis is used to illustrate SEM results predicting hourly wage (see Figure 2). This followed the same analytical logic as Figure 1 above. Here, the analysis validates the all the hypotheses and, as expected, the final model fits the data well, as evidenced by a highly significant chi-square, $\chi^{2}=915.74, \mathrm{CFI}>.95$, and RMSEA<.05. The final model explains $36 \%$ of the variance in physical attractiveness and $26 \%$ of wage. All path coefficients are significant $(\mathrm{p}<.05)$ and are in predicted directions. Specifically, the indirect path of skin color operating on hourly wage, as mediated by physical attractiveness, is significant. The indirect effect is $(.57)(.45)=.26$. The results from the path analysis confirm the moderating effect of gender on the relationship between skin tone and wage and attractiveness and wage, such that lighter-complected and more attractive black 
women get a higher hourly wage than lighter-complected and more attractive black men $(\mathrm{p}<.05)$

[Figure 2 is about here]

In Figure 3, a path analysis diagram is shown for the final model that includes all hypothesized paths to job quality. Before turning to a discussion of results, we note the model fit statistics indicate an excellent fit of the final model to the data. Specifically, in accordance with empirical standards the chi-square test statistic is non-significant $(\chi 2=$ 896); the value of CFI (.98) exceeds .95; and RMSEA value (.04) is below the suggested threshold of .5. In judging the hypothesized relationships between the key study variables, it is worth noting that both the direct and indirect (through physical attractiveness) paths from skin tone to job quality are significant $(\mathrm{p}<.01)$ and positive. This means that lightercomplected black young adults are more likely than their darker-complected counterparts to enjoy better-quality jobs. Finally, our data support the view that gender moderates the relationships between skin tone and job quality and between attractiveness and job quality. In both cases, these relationships are stronger for black women than for black men. Overall, approximately 35 and $21 \%$ of the variance in physical attractiveness and job quality, respectively, is explained by the predictors in the final model.

[Figure 3 is about here]

\section{Discussion}

Research on colorism has a long history. As early as the mid- $20^{\text {th }}$ century, pioneering research of Edwards (1959), Frazier (1957), and Myrdal (1944) identified skin 
tone is a marker of social status within the black population. These scholars observed a skin color hierarchy that privileged those blacks whose skin shade was closer to that of the dominant group. It has also long been noted that the skin color hierarchy in the United States is traceable to the period of slavery, when white owners granted privileges to slaves with partial white heritage (Bodenhorn 2002; Bodenhorn and Ruebeck 2007; Hunter 2007; Keith and Herring 1991; Saperstein and Gullickson 2013). The bulk of scholarly work on colorism so far suggests that lighter-complected blacks continue to enjoy considerable socio-economic advantages over their darker-complected counterparts (Hersch 2006; Hochschild and Weaver 2007; Ryabov 2013). However, some studies have contested the dominant view that colorism still persists and have shown that the skin color hierarchy has diminished in the Post-Civil Rights era (Goering 1972; Gullickson 2005; Udry et al. 1971). Another strand of research that has been inspirational for our work is interdisciplinary research in sociology, psychology and economics examining the impact of physical attractiveness on a range of socio-economic outcomes (Fletcher 2002; French et al. 2009; Hosoda et al. 2003; Zebrowitz et al. 2002). This literature is predominantly color blind - it typically views beauty as a status characteristic extant in all contexts and stable and invariable across racial categories. The current paper shifts the focus of this line of research by suggesting that, because racism and colorism permeate nearly all aspects of American society in very subtle ways, Eurocentric definitions of beauty are imposed on racial minorities and this results in the value of attractiveness being confounded with that of phenotype. The argument presented questions the taken-for-granted assumptions on which most of the physical attractiveness research is based on and highlights socially contingent nature of physical attractiveness for black status attainment. 
Using the longitudinal data from the National Longitudinal Study of Adolescent Health (the Add Health), the current study bridges literatures on colorism and physical attractiveness and examines the roles of skin color, physical attractiveness and gender on attained social status for black young adults, while controlling for family backgrounds and other factors. The purpose of this study was to test: (1) the strength of the relationship between physical attractiveness and social status attainment among black young adults; (2) whether skin tone is an antecedent with attractiveness mediating the relationship between skin tone and status attainment; and (3) whether gender moderates the relationship between skin tone and measures of the attained status (educational attainment, hourly wage and job quality) and the relationship between skin tone and the aforementioned measures of status. Thus, this study is unique among the physical attractiveness studies in a number of ways: (1) we simultaneously investigate three outcomes that capture different dimensions of status attainment and social mobility, namely educational attainment, wage and job quality; (2) we focus of African-Americans, an underrepresented minority group in research on physical attractiveness; (3) we examine the mediating effect of physical attractiveness on the relationship between skin tone and status attainment.

All in all, we found that physical attractiveness is conducive to educational and occupational success of young black adults. Physically attractive young blacks of both genders are predicted to have higher educational attainment, higher wages and betterquality jobs that their less attractive counterparts. Furthermore, the results of this study do not support the minority view (e.g., Gullickson 2005) that skin tone has lost its significance as one of the most influential dimensions of social stratification for blacks. On the contrary, the Add Health data strongly support the dominant view that skin color remains a 
significant determinant of a black person's chances of moving up in the social structure (e.g., Hochschild and Weaver 2007; Monk 2015). However, this is only part of the picture. Arguably, the most important contribution of this paper to the literature on colorism is that it shows that physical attractiveness mediates the relationship between skin tone and status attainment for black young adults. It is important to mention that, regardless of what outcome is used (educational attainment, wage or job quality), an indirect effect of phenotype on status attainment through attractiveness is positive and significant $(\mathrm{p}<.5)$. This is a novel contribution because it links the physical attractiveness research (Fletcher 2002; Hamermesh 2011; Hosoda et al. 2003) and the academic field of colorism studies (Hochschild and Weaver 2007; Hill 2002; Hunter 2002, 2007). Finally, we found that gender acts as the moderator of the relationship between skin tone and physical attractiveness, on the one hand, and status attainment measures, on the other hand. The only exception was an interaction effect of skin tone and gender on educational attainment that was nonsignificant in the full model. In all but one case (mentioned above), the effects of skin color and attractiveness on status attainment on educational attainment, wage and job quality were stronger for black women more than black men. This illustrates that: (1) gender is bound up with colorism - lightness of skin has more bearing on the advancement of black women than black men; and (2) there is a double standard of beauty - while attractiveness matters for black men, for black women it is vital.

\section{Limitations}


There are several limitations to this study. First, phenotypic differences include, but not limited to, skin tone. Skin tone does not encompass all factors that are considered part of the Eurocentric phenotype. Therefore, if other phenotypic features, such as shape of eyes, lip thickness and others, were included as predictors of educational attainment, hourly wage and job quality, our results could have been different. The Add Health did not collect this information. However, the survey contains interviewer-assessed information on eye and hair color. Unfortunately, these indicators are two dimensions of phenotype that can be easily modified on a daily basis: hair can be dyed, and colored contact lenses allow anyone to change their natural eye color. Moreover, it is unclear how eye color translates into a scale and whether such a scale is analytically meaningful; i.e., are blue eyes closer to ideal white beauty standards than green eyes; are green eyes closer than hazel, etc.? Second, both skin tone and attractiveness are assessed by an interviewer. Although the Add Health interviewers went through an extensive week-long training (Richmond, et al. 2012), we cannot rule out that the interviewer bias was not present in our data. In order to check if the race of the interviewer influences his or her perception of skin darkness, we conducted additional analyses (not shown) which included interviewer's race as one of the controls, but the effect of this predictor was consistently insignificant. It is also worth mention that a number of prior studies using the Add Health data have shown that systematic interviewer bias does not appear to be a concern (Reece 2016; Ryabov 2016; Sims 2012). Moreover, the fact that the key independent variables - skin tone and physical attractiveness - were derived from interviewer ratings can be interpreted as the strength of this study. The interviewer's assessments of skin tone and physical attractiveness are close to those of an external observer in a larger society and are not subject to self-assessment bias. How 
people are perceived by external observers, e.g. interviewers, to a large extent reflects the treatment they receive by individuals and social institutions alike.

\section{Conclusion}

Our main finding is that colorism strikes at the very core of what it means to be black today. Moreover, we found that stratifications by physical attractiveness and phenotype among blacks overlap to a high degree. Thus, the proximity to (or distance from) Eurocentric phenotype for blacks can still be used as a marker or indicator of both beauty and social status. The main reason it is so are the Eurocentric standards of beauty that are complicit in fostering colorism and affect black women more than black men. The fact that these standards continue to be applied to blacks is also indicative of the fact that the "black is beautiful" movement has not been able to alter the color bias in black community. An unfortunate outcome is that lighter-complected blacks are more likely to achieve a higher status and better opportunities for upward social mobility than their darker-complected co-ethnics who are, as of now, are at the bottom of the status hierarchy in the American society.

Although social scientists have a broad understanding of the effects of colorism, the mechanisms are not fully understood, and exploring the connection between phenotype and attractiveness can push forward our understanding of how colorism functions in the United States. Our findings show that physical attractiveness is one of the mechanisms through which colorism affects social status attainment of blacks. Future research should attempt to explore other covert and overt mechanisms through which colorism affects daily 
lives of blacks and other minorities and to investigate the themes of resistance to colorism and the Eurocentric standards of beauty on the part of black men and women. We emphasize that this article uses only one phenotypic characteristic - skin tone - an interviewer-reported measure of physical attractiveness and a limited number of social status indicators, so future research is warranted to explore other methodologies and indicators of socio-economic progress. Based upon the findings of this study, we also encourage future research to focus on other variables that may serve to mediate the relationship between phenotype and social status.

\section{References}

Allen, W., Telles, E., \& Hunter, M. (2000). Skin color, income and education: A comparison of African Americans and Mexican Americans. National Journal of Sociology, 12(1), 129-180.

Awad, G. H., Norwood, C., Taylor, D. S., Martinez, M., McClain, S., Jones, B., Holman, A., \& Chapman-Hilliard, C. (2015). Beauty and body image concerns among African American college women. Journal of Black Psychology, 41(6), 540-564.

Baert, S., \& Decuypere, L. (2014). Better sexy than flexy? A lab experiment assessing the impact of perceived attractiveness and personality traits on hiring decisions. Applied Economics Letters, 21(9), 597-601.

Bearman, P. S., Moody, J., \& Stovel, K. (2004). Chains of affection: The structure of adolescent romantic and sexual networks1. American Journal of Sociology, 110(1), 4491. 
Bergad, L. (2007). The Comparative Histories of Slavery in Brazil, Cuba, and the United States. Cambridge University Press.

Bodenhorn, H. (2002). The mulatto advantage: The biological consequences of complexion in rural antebellum Virginia. Journal of Interdisciplinary History, 33(1), 2146.

Bodenhorn, H. (2006). Colorism, complexion homogamy, and household wealth: Some historical evidence. American Economic Review, 96(2), 256-260.

Bodenhorn, H., \& Ruebeck, C. S. (2007). Colourism and African-American wealth: evidence from the nineteenth-century south. Journal of Population Economics, 20(3), 599-620.

Borrell, L. N., Kiefe, C. I., Williams, D. R., Diez-Roux, A. V., \& Gordon-Larsen, P. (2006). Self-reported health, perceived racial discrimination, and skin color in African Americans in the CARDIA study. Social Science \& Medicine, 63(6), 1415-1427.

Bratter, J. L., \& O’Connell, H. A. (2017). Multiracial identities, single race history: Contemporary consequences of historical race and marriage laws for racial classification. Social Science Research, 68, 102-116.

Cole, S. (2005). Capitalism and freedom: Manumissions and the slave market in Louisiana, 1725-1820. The Journal of Economic History, 65(4), 1008-1027.

Coleman, J. S. (1988). Social capital in the creation of human capital. American Journal of Sociology, 94:95-120.

Dodoo, F. N. A. (1997). Assimilation differences among Africans in America. Social Forces, 76(2), 527-546. 
Dixon, A. R., \& Telles, E. E. (2017). Skin color and colorism: Global research, concepts, and measurement. Annual Review of Sociology, 43, 405-424.

Eastwick, P. W., Luchies, L. B., Finkel, E. J., \& Hunt, L. L. (2014). The predictive validity of ideal partner preferences: A review and meta-analysis. Psychological Bulletin, $140(3), 623$.

Edwards, G. F. (1959). The Negro Professional Class. Glencoe, IL: The Free Press.

Fletcher, J. M. (2009). Beauty vs. brains: Early labor market outcomes of high school graduates. Economics Letters, 105(3), 321-325.

Frazier, F. (1957). Black Bourgeoisie: The Rise of the New Middle Class in the United States. New York: The Free Press.

French, M. T. (2002). Physical appearance and earnings: Further evidence. Applied Economics, 34(5), 569-572.

French, M. T., Robins, P. K., Homer, J. F., \& Tapsell, L. M. (2009). Effects of physical attractiveness, personality, and grooming on academic performance in high school. Labour Economics, 16(4), 373-382.

Furnham, A., Badmin, N., \& Sneade, I. (2002). Body image dissatisfaction: Gender differences in eating attitudes, self-esteem, and reasons for exercise. The Journal of Psychology, 136(6), 581-596.

Goldsmith, A. H., Hamilton, D., \& Darity, W. (2007). From dark to light: Skin color and wages among African-Americans. Journal of Human Resources, 42(4), 701-738.

Goering, J. M. (1972). Changing perceptions and evaluations of physical characteristics among blacks: 1950-1970. Phylon (1960-), 33(3), 231-241.

Gowin, E. (1915). The Executive and His Control. New York: Macmillan. 
Grabe, S., \& Hyde, J. S. (2006). Ethnicity and body dissatisfaction among women in the United States: A meta-analysis. Psychological Bulletin, 132, 622- 640

Grabe, S., Ward, L. M., \& Hyde, J. S. (2008). The role of the media in body image concerns among women: a meta-analysis of experimental and correlational studies. Psychological Bulletin, 134(3), 460-476.

Greitemeyer, T. (2010). Effects of reciprocity on attraction: The role of a partner's physical attractiveness. Personal Relationships, 17(2), 317-330.

Gray, A. W., \& Boothroyd, L. G. (2012). Female facial appearance and health. Evolutionary Psychology, 10(1), 66-77.

Gullickson, A. (2005). The significance of color declines: A re-analysis of skin tone differentials in post-civil rights America. Social Forces, 84(1), 157-180.

Hair, J.F., Black, W.C., Babin, B.J., Anderson, R.E., \& Tatham, R. L. (2010). Multivariate data analysis: A global perspective. Upper Saddle River, NJ: Prentice Hall.

Hall, R. E. (2003). Skin color as post-colonial hierarchy: A global strategy for conflict resolution. The Journal of Psychology, 137(1), 41-53.

Hall, R. E. (2005). From the psychology of race to the issue of skin color for people of African descent. Journal of Applied Social Psychology, 35(9), 1958-1967.

Hamermesh, D. (2011). Beauty Pays: Why Attractive People are more Successful? Princeton, NJ: Princeton University Press.

Hannon, L., DeFina, R., \& Bruch, S. (2013). The relationship between skin tone and school suspension for African Americans. Race and Social Problems, 5(4), 281-295. 
Harris, K. M., Halpern, C. T., Whitsel, E., Hussey, J., Tabor, J., Entzel, P., \& Udry, J. R. (2009). The national longitudinal study of adolescent health: Research design. Available at http://www.cpc.unc.edu/projects/addhealth/design.

Harvey, R. D., LaBeach, N., Pridgen, E., \& Gocial, T. M. (2005). The intragroup stigmatization of skin tone among Black Americans. Journal of Black Psychology, 31(3), 237-253.

Haynie, D. L. (2001). Delinquent peers revisited: Does network structure matter? American Journal of Sociology, 106(4), 1013-1057.

Hersch, J. (2006). Skin-tone effects among African Americans: Perceptions and reality. American Economic Review, 96(2), 251-255.

Hill, M. E. (2002). Skin color and the perception of attractiveness among African Americans: Does gender make a difference? Social Psychology Quarterly, 65(1): 77-91.

Hochschild, J. L., \& Weaver, V. (2007). The skin color paradox and the American racial order. Social Forces, 86(2), 643-670.

Hosoda, M., Stone-Romero, E. F., \& Coats, G. (2003). The effects of physical attractiveness on job-related outcomes: A meta-analysis of experimental studies. Personnel Psychology, 56(2), 431-462.

Hunter, M. L. (2002). "If you're light you're alright" light skin color as social capital for women of color. Gender \& Society, 16(2), 175-193.

Hunter, M. (2007). The persistent problem of colorism: Skin tone, status, and inequality. Sociology Compass, 1(1), 237-254.

Jæger, M. M. (2011). “A thing of beauty is a joy forever”? Returns to physical attractiveness over the life course. Social Forces, 89(3), 983-1003. 
Judge, T. A., Hurst, C., \& Simon, L. S. (2009). Does it pay to be smart, attractive, or confident (or all three)? Relationships among general mental ability, physical attractiveness, core self-evaluations, and income. Journal of Applied Psychology, 94(3), 742.

Keith, V. M., Nguyen, A. W., Taylor, R. J., Mouzon, D. M., \& Chatters, L. M. (2017). Microaggressions, discrimination, and phenotype among African Americans: A latent class analysis of the impact of skin tone and BMI. Sociological inquiry, 87(2), 233255.

Kolchin P. (2003). American Slavery, 1619-1877. New York: Farrar, Straus and Giroux.

Langlois, J. H., Kalakanis, L., Rubenstein, A. J., Larson, A., Hallam, M., \& Smoot, M. (2000). Maxims or myths of beauty? A meta-analytic and theoretical review. Psychological Bulletin, 126(3), 390-423.

Maddox, K. B., \& Gray, S. A. (2002). Cognitive representations of Black Americans: Reexploring the role of skin tone. Personality and Social Psychology Bulletin, 28(2), 250-259.

Marlowe, C. M., Schneider, S. L., \& Nelson, C. E. (1996). Gender and attractiveness biases in hiring decisions: Are more experienced managers less biased? Journal of Applied Psychology, 81(1), 11-21.

Mbure, W.G., \& Aubrey, J. S. (2017). A transnational analysis of skin tone ideals in cosmetic advertisements in women's lifestyle magazines. Howard Journal of Communications, 28(4), 339-355. 
Meltzer, A. L., McNulty, J. K., Jackson, G. L., \& Karney, B. R. (2014). Sex differences in the implications of partner physical attractiveness for the trajectory of marital satisfaction. Journal of Personality and Social Psychology, 106(3), 418.

Mobius, M. M., \& Rosenblat, T. S. (2006). Why beauty matters. American Economic Review, 96(1), 222-235.

Model, S. (2008). West Indian Immigrants: A Black Success Story? New York: Russell Sage Foundation.

Monk Jr, E. P. (2015). The cost of color: Skin color, discrimination, and health among African-Americans. American Journal of Sociology, 121(2), 396-444.

Myrdal, G. (1944). An American dilemma: The Negro problem and modern democracy. New York: Harper and Row.

Nedelec, J. L., \& Beaver, K. M. (2014). Physical attractiveness as a phenotypic marker of health: an assessment using a nationally representative sample of American adults. Evolution and Human Behavior, 35(6), 456-463.

Osborne, J. W. (2010). Improving your data transformations: Applying the BoxCox transformation. Practical Assessment, Research \& Evaluation, 15(12), 2-9.

Parmer, T., Arnold, M. S., Natt, T., \& Janson, C. (2004). Physical attractiveness as a process of internalized oppression and multigenerational transmission in African American families. The Family Journal, 12(3), 230-242.

Perrin, F. A. C. (1921). Physical attractiveness and repulsiveness. Journal of Experimental Psychology, 4(3), 203-217.

Pfeifer, C. (2012). Physical attractiveness, employment and earnings. Applied Economics Letters, 19(6), 505-510. 
Reece, R. L. (2016). What are you mixed with: The effect of multiracial identification on perceived attractiveness. The Review of Black Political Economy, 43(2), $139-147$.

Reither, E. N., Hauser, R. M., \& Swallen, K. C. (2009). Predicting adult health and mortality from adolescent facial characteristics in yearbook photographs. Demography, 46(1), 27-41.

Richmond, T. K., Austin, S. B., Walls, C. E., \& Subramanian, S. V. (2012). The association of body mass index and externally perceived attractiveness across race/ethnicity, gender, and time. Journal of Adolescent Health, 50(1), 74-79.

Robins, P. K., Homer, J. F., \& French, M. T. (2011). Beauty and the labor market: accounting for the additional effects of personality and grooming. Labour, 25(2), 228-251.

Ruffle, B. J., \& Shtudiner, Z. E. (2014). Are good-looking people more employable? Management Science, 61(8), 1760-1776.

Ryabov, I. (2013). Colorism and school-to-work and school-to-college transitions of African American adolescents. Race and Social Problems, 5(1), 15-27.

Ryabov, I. (2016). Educational outcomes of Asian and Hispanic Americans: The significance of skin color. Research in Social Stratification and Mobility, 44, 1-9.

Saperstein, A., \& Gullickson, A. (2013). A "Mulatto Escape Hatch" in the United States? Examining evidence of racial and social mobility during the Jim Crow era. Demography, 50(5), 1921-1942.

Schermelleh-Engel, K., Moosbrugger, H., \& Müller, H. (2003). Evaluating the fit of structural equation models: Tests of significance and descriptive goodness-of-fit measures. Methods of Psychological Research Online, 8(2), 23-74. 
Schreck, C. J., Fisher, B. S., \& Miller, J. M. (2004). The social context of violent victimization: A study of the delinquent peer effect. Justice Quarterly, 21(1), 23-47.

Schwarz, S., \& Hassebrauck, M. (2012). Sex and age differences in mate-selection preferences. Human Nature, 23(4), 447-466.

Sims, J. P. (2012). Beautiful stereotypes: The relationship between physical attractiveness and mixed race identity. Identities, 19(1), 61-80.

Solorzano, D., Ceja, M., \& Yosso, T. (2000). Critical race theory, racial microaggressions, and campus racial climate: The experiences of African American college students. Journal of Negro Education, 60-73.

Sowell, T. (1978). Essay and Data on American Ethnic Groups. Washington, DC: Urban Institute.

Thompson, M. S., \& Keith, V. M. (2001). The blacker the berry: Gender, skin tone, self-esteem, and self-efficacy. Gender \& Society, 15(3), 336-357.

Trekels, J., Eggermont, S., Koppen, E., \& Vandenbosch, L. (2018). Beauty ideals from reality television and young women's tanning behavior: An internalization and selfobjectification perspective. Communication Quarterly, 66(3), 325-343.

Udry, J. R., Bauman, K. E., \& Chase, C. (1971). Skin color, status, and mate selection. American Journal of Sociology, 76(4), 722-733.

Wade, T. J., \& Bielitz, S. (2005). The differential effect of skin color on attractiveness, personality evaluations, and perceived life success of African Americans. Journal of Black Psychology, 31(3), 215-236.

Waller, W. (1937). The rating and dating complex. American Sociological Review, 2(5), 727-34 
Weitz, R. (2001). Women and their hair: Seeking power through resistance and accommodation. Gender \& Society, 15(5), 667-686.

Wickrama, K. A. S., Simons, L. G., \& Baltimore, D. (2012). The influence of ethnicity and adverse life experiences during adolescence on young adult socioeconomic attainment: The moderating role of education. Journal of Youth and Adolescence, 41(11), $1472-1487$.

Zebrowitz, L. A., Hall, J. A., Murphy, N. A., \& Rhodes, G. (2002). Looking smart and looking good: Facial cues to intelligence and their origins. Personality and Social Psychology Bulletin, 28(2), 238-249. 
Table 1 Weighted Means and Standard Deviations of Independent Variables by Gender $(\mathrm{N}=2,456)$

\begin{tabular}{lcccc}
\hline & \multicolumn{2}{c}{ Males (n=1,088) } & \multicolumn{2}{c}{ Females (n=1,368) } \\
\cline { 2 - 4 } & $\begin{array}{c}\text { Weighted } \\
\text { Mean }\end{array}$ & St. Deviation & $\begin{array}{c}\text { Weighted } \\
\text { Mean }\end{array}$ & St. Deviation \\
\hline Outcome Measures (Wave 4) & & & & \\
Educational Attainment & 2.26 & 0.42 & 2.28 & 0.41 \\
Hourly Wages & 2.44 & 0.49 & 2.40 & 0.48 \\
Job Quality & 1.32 & 0.41 & 1.28 & 0.40 \\
Individual-Level Variables & & & & \\
Attractiveness (Waves 1-4) & 2.31 & 0.58 & 2.78 & 0.56 \\
Skin Tone (Wave 3) & 1.80 & 0.45 & 2.00 & 0.43 \\
Family Effects (Wave 1) & & & & \\
Family SES & 3.57 & 0.72 & 3.51 & 0.71 \\
Two-Parent Household & 0.43 & 0.43 & 0.44 & 0.42 \\
Parental Involvement & 0.50 & 0.34 & 0.56 & 0.35 \\
Parental Attachment & 4.10 & 0.63 & 4.23 & 0.62 \\
Parental Engagement & 3.87 & 0.76 & 4.06 & 0.74 \\
Other Individual-Level Controls & & & & \\
Age (Wave 4) & 28.08 & 0.47 & 28.07 & 0.47 \\
Married (Wave 4) & 0.39 & 0.45 & 0.37 & 0.45 \\
GPA (Wave 1) & 2.56 & 0.29 & 2.57 & 0.29 \\
\hline
\end{tabular}

a These variables are transformed using the Box-Cox family of log-linear transformations. 
Table 2 Bivariate Correlations Between Physical Attractiveness, Skin Tone and The Outcome Variables

\begin{tabular}{|c|c|c|c|c|c|c|c|c|c|c|c|c|c|c|}
\hline \multirow{2}{*}{\begin{tabular}{|l} 
Variable \\
1. Educational \\
Attainment
\end{tabular}} & 1 & 2 & 3 & 4 & 5 & 6 & 7 & 8 & 9 & 10 & 11 & 12 & 13 & 14 \\
\hline & & & & & & & & & & & & & & \\
\hline 2. Hourly Wage & $.63^{* *}$ & & & & & & & & & & & & & \\
\hline 3. Job Quality & $.48^{* *}$ & $.55^{* *}$ & & & & & & & & & & & & \\
\hline $\begin{array}{l}\text { 4. Physical } \\
\text { Attractiveness }\end{array}$ & $.24 * *$ & $.29 * *$ & $.28 * *$ & & & & & & & & & & & \\
\hline 5. Skin Tone & $.33 * *$ & $.36 * *$ & $.39 * *$ & $.44 * *$ & & & & & & & & & & \\
\hline 6. Gender (Male) & -.08 & $.27 * *$ & $.26 * *$ & $-36 * *$ & $-.22 *$ & & & & & & & & & \\
\hline 7. Family SES & $.33^{* *}$ & $.28^{* *}$ & $.18^{*}$ & $.21 *$ & .07 & -.00 & & & & & & & & \\
\hline $\begin{array}{l}\text { 8. Two-Parent } \\
\text { Household }\end{array}$ & $.14^{*}$ & $.16^{*}$ & .10 & $.23 *$ & $.19 *$ & .02 & $.35^{* *}$ & & & & & & & \\
\hline $\begin{array}{l}\text { 9. Parental } \\
\text { Involvement }\end{array}$ & .11 & .08 & $.13^{*}$ & $.18^{*}$ & $.16^{*}$ & $-.13 *$ & $.24 * *$ & $.30 * *$ & & & & & & \\
\hline $\begin{array}{l}\text { 10. Parental } \\
\text { Attachment }\end{array}$ & $.13^{*}$ & .10 & .06 & .11 & .03 & -.06 & $.16^{*}$ & $.36 * *$ & $.44 * *$ & & & & & \\
\hline $\begin{array}{l}\text { 11. Parental } \\
\text { Engagement }\end{array}$ & .10 & .09 & .05 & $.14^{*}$ & $.15^{*}$ & -.08 & $.17^{*}$ & $.32 * *$ & $.38 * *$ & $.41 * *$ & & & & \\
\hline 12. Age & $.17^{*}$ & $.12 *$ & $.14 *$ & -.01 & -.03 & .02 & -.03 & .02 & -.04 & .02 & .05 & & & \\
\hline 13. Married & -.06 & .09 & -.07 & $.18^{*}$ & $.17 *$ & .10 & .05 & .08 & .10 & $.13 *$ & .08 & $.57 * *$ & & \\
\hline 14. GPA & $.34 * *$ & $.28 * *$ & $.12 *$ & $.23 * *$ & $.13^{*}$ & -.08 & $.31 * *$ & $.25 * *$ & $.27 * *$ & $.20^{*}$ & $.25 * *$ & $.12 *$ & 0.08 & \\
\hline
\end{tabular}

Note: $* \mathrm{p}<.05 ; * * \mathrm{p}<.01$. 


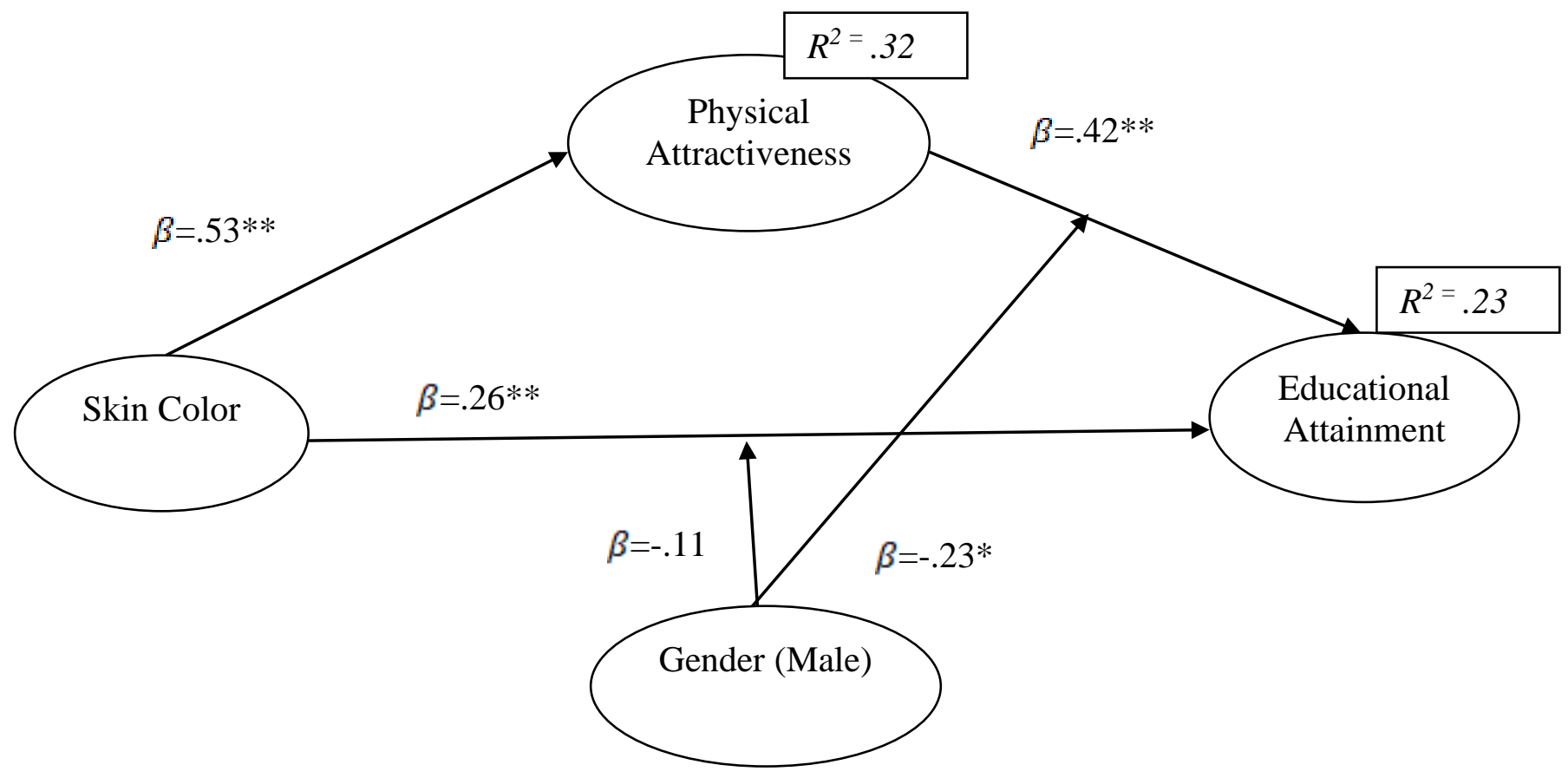

Figure 1 Structural Model Predicting Educational Attainment among Black Young Adults. Note: The Estimation Results for the Control Variables and Errors Are Not Shown for Reasons of Space. $\chi^{2}=876.16 ; \mathrm{CFI}=.97, \mathrm{RMSEA}=0.04 ; * \mathrm{p}<.05 ; * * \mathrm{p}<.01$. 


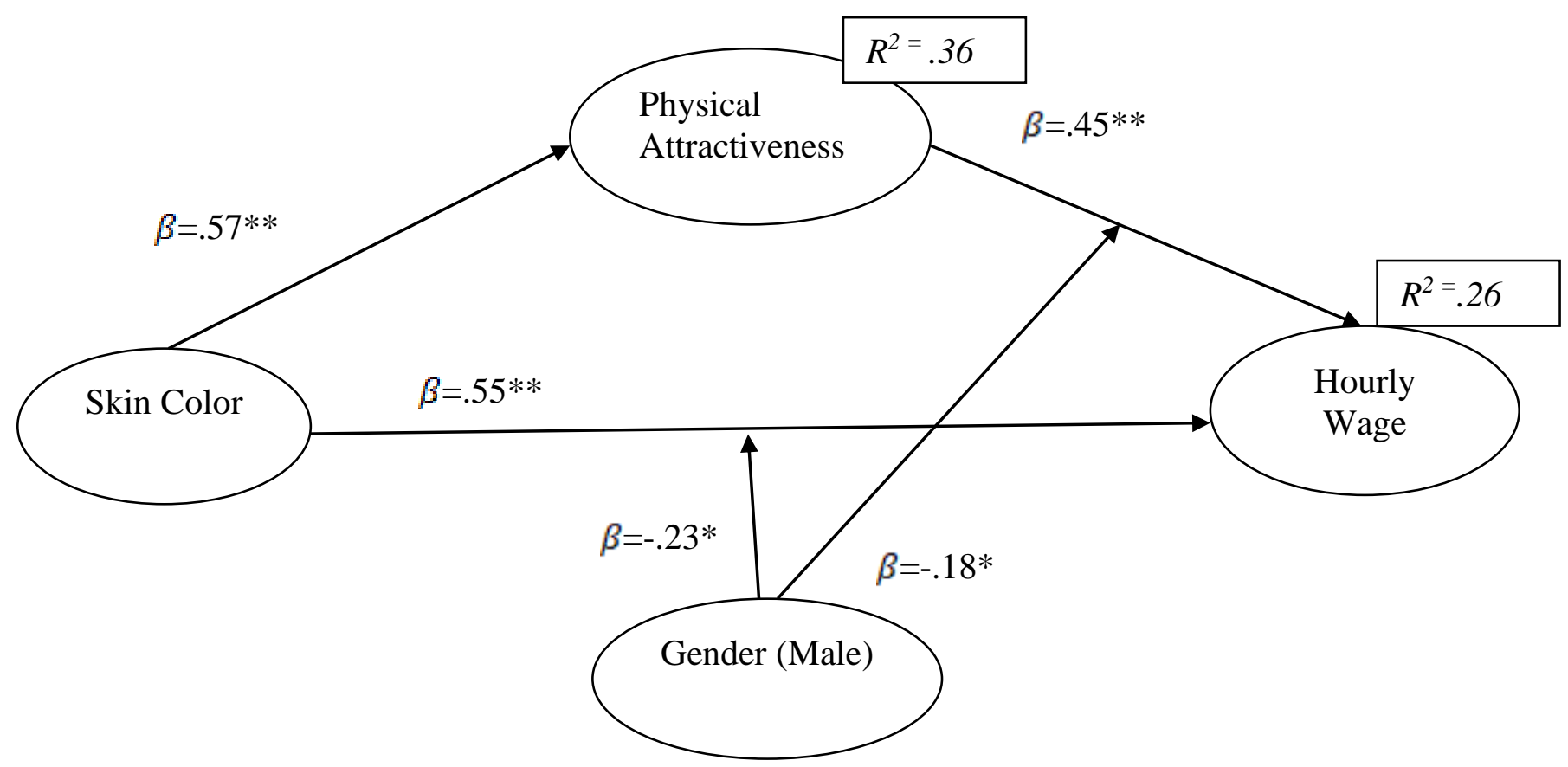

Figure 2 Structural Model Predicting Hourly Wage among Black Young Adults. The Note: The Estimation Results for the Control Variables and Errors Are Not Shown for Reasons of Space. $\chi 2=915.74 ; \mathrm{CFI}=.99, \mathrm{RMSEA}=.04 ; * \mathrm{p}<.05 ; * * \mathrm{p}<.01$. 


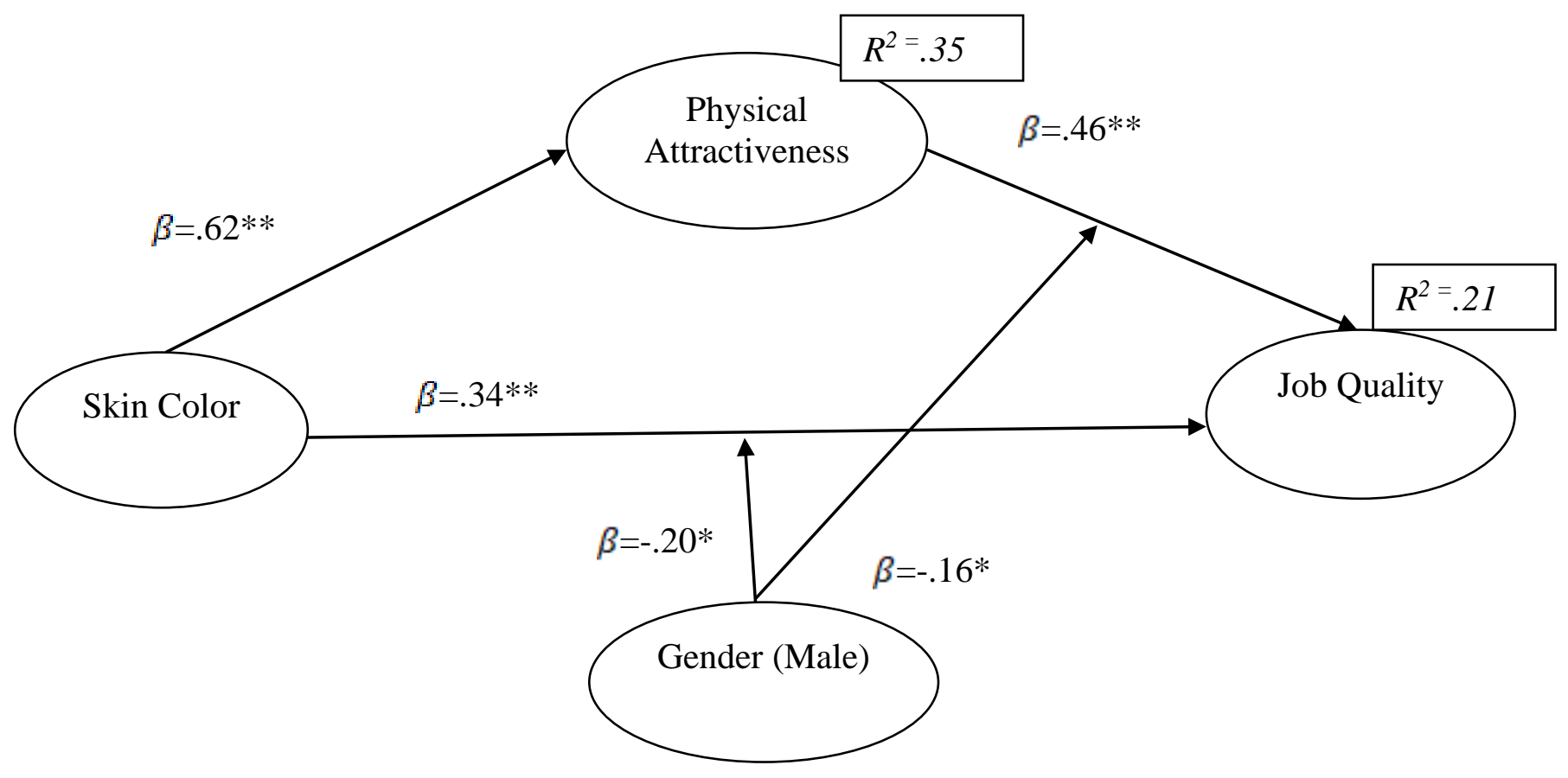

Figure 3 Structural Model Predicting Job Quality among Black Young Adults. The Note: The Estimation Results for the Control Variables and Errors Are Not Shown for Reasons of Space. $\chi 2=896.10 ; \mathrm{CFI}=.98, \mathrm{RMSEA}=.04 ; * \mathrm{p}<.05 ; * * \mathrm{p}<.01$. 